Revista Destaques Acadêmicos, Lajeado, v. 12, n. 3, 2020. ISSN 2176-3070

DOI: http://dx.doi.org/10.22410/issn.2176-3070.v12i3a2020.2683

http://www.univates.br/revistas

\title{
AVALIAÇÃO DAS BOAS PRÁTICAS DE MANIPULAÇÃO EM LANCHONETE DA CIDADE DE POMBAL - PB DURANTE O PREPARO DE MOLHO ARTESANAL: ANÁLISES MICROBIOLÓGICAS E ESTABILIDADE FÍSICO- QUÍMICA NO ARMAZENAMENTO
}

\author{
Bruno Fonsêca Feitosa ${ }^{1}$, Charlene Maria de Alcantara ${ }^{1}$, \\ Weverton Pereira de Medeiros ${ }^{2}$, Elaine Juliane da Costa Silva ${ }^{3}$, \\ Wilian Vito de Oliveira Santos ${ }^{4}$, João Vitor Fonseca Feitoza ${ }^{5}$, \\ Alfredina dos Santos Araujo ${ }^{6}$
}

\begin{abstract}
Resumo: Os alimentos prontos para o consumo surgiram através da busca pela praticidade, sendo oferecidos por alguns estabelecimentos que não possuem condições higiênico-sanitárias adequadas para a comercialização. Objetivou-se avaliar as Boas Práticas de Manipulação em uma lanchonete localizada na cidade de Pombal - PB, durante a preparação de molho artesanal, analisar sua qualidade microbiológica e estabilidade físico-química no armazenamento. Foi utilizado um checklist para avaliação das condições higiênico-sanitárias, baseado na Resolução da Diretoria Colegiada (RDC) $\mathrm{n}^{\circ} 275$, de 21 de outubro de 2002 e RDC n n $^{\circ} 16$, de 15 de setembro de 2004. Também foi avaliada a qualidade microbiológica em contraste com um molho industrial e a estabilidade físico-química durante 12 dias de armazenamento sob temperatura ambiente e de refrigeração. Ao menos $45 \%$ dos itens analisados foram não conformes quanto as edificações e instalações; equipamentos, móveis e utensílios; manipuladores; e produção e transporte do alimento. As análises microbiológicas indicaram contagem $<3,0$ Número Mais Provável (NMP)/g para Coliformes a 35 e $45^{\circ} \mathrm{C}$, além da ausência de Salmonella sp. em $25 \mathrm{~g}$ das amostras, provavelmente devido ao $\mathrm{pH}$ ácido e a
\end{abstract}

1 Acadêmicos de Engenharia de Alimentos, CCTA/UFCG, Pombal-PB

2 Mestre em Sistemas Agroindustriais, CCTA/UFCG, Pombal-PB

3 Mestranda em Sistemas Agroindustriais, CCTA/UFCG, Pombal-PB

4 Técnico de Laboratório, CCTA/UFCG, Pombal-PB

5 Docente do Curso de Licenciatura em Química, IFRN, Apodi-RN

6 Docente do Curso de Engenharia de Alimentos, CCTA/UFCG, Pombal-PB 
aplicação de tratamento térmico durante a preparação. O molho artesanal demonstrou boa estabilidade físico-química em temperatura refrigerada, durante 12 dias de armazenamento. Apesar da boa qualidade microbiológica dos molhos, a lanchonete avaliada na cidade de Pombal - PB necessita de adequações aos requisitos exigidos para atender a regulamentação sanitária com o auxílio dos órgãos competentes.

Palavras-chave: Alimentos artesanais. Lista de verificação. Segurança dos alimentos.

\section{INTRODUÇÃO}

Os alimentos prontos para o consumo surgiram com a mudança nos hábitos alimentares dos consumidores. Os novos estabelecimentos apresentam diversas opções de produtos, complementos alimentares e preparações com perfil artesanal. No entanto, muitos desses locais não possuem condições físicas e higiênico-sanitárias adequadas para preparação e comercialização (CÂNDIDO et al., 2019).

A Agência Nacional de Vigilância Sanitária (ANVISA), através da Resolução da Diretoria Colegiada (RDC) no 216, de 15 de setembro de 2004, define as Boas Práticas de Manipulação (BPM) como os procedimentos que devem ser adotados por serviços de alimentação a fim de garantir a qualidade higiênico-sanitária e a conformidade dos alimentos com a legislação sanitária (BRASIL, 2004).

$\mathrm{O}$ processamento e armazenamento de alimentos de forma artesanal merecem atenção, devido as possíveis alterações físico-químicas e microbiológicas (SOUZA et al., 2015; CORTESE et al., 2016). Para garantir padrões diferenciados para essa produção artesanal e de pequeno porte, a ANVISA também publicou a RDC n 49, de 31 de outubro de 2013, que concede suporte a vigilância sanitária frente ao microempreendedor individual de alimentos (BRASIL, 2013).

Diversas pesquisas investigaram as Boas Práticas de Fabricação/ Manipulação em diferentes tipos de estabelecimentos, como restaurante selfservice (BELTRÃO et al., 2017), escolas de educação infantil (FORTES et al., 2017), comércio de produtos de origem animal (MAIA et al., 2017), restaurante universitário (MEDEIROS et al., 2017), cantina escolar (VERDUM et al., 2017; MACÊDO e LOPES, 2018) e quiosque (SANTOS et al., 2018). Neste contexto, a maioria dos relatos na literatura revelaram condições higiênico-sanitárias insatisfatórias. Além disso, Melo et al. (2012) evidenciaram que os estudos que visam avaliar as características de molhos alimentícios e seu comportamento durante o armazenamento ainda são incipientes.

Assim, objetivou-se avaliar as Boas Práticas de Manipulação em uma lanchonete localizada na cidade de Pombal - PB, durante a preparação de molho artesanal, analisar sua qualidade microbiológica em contraste com um molho industrial, bem como a estabilidade físico-química no armazenamento sob temperatura ambiente e de refrigeração. 


\section{METODOLOGIA}

\subsection{Avaliação das Boas Práticas de Manipulação}

Na cidade de Pombal, Paraíba, Brasil, que possui uma área de $889 \mathrm{Km}^{2}$ e uma população estimada de 32.801 habitantes, em 2019 (IBGE, 2019), os dados foram coletados entre 15 e 20 de julho de 2019, sendo obtidos em uma lanchonete. Após a autorização do proprietário com acordo de completo sigilo e anonimato das informações recolhidas, foi empregado o método de observação direta e preenchimento de uma lista de verificação (checklist). O checklist das BPM foi baseado na RDC $\mathrm{n}^{\circ} 275$, de 21 de outubro de 2002, bem como na RDC $\mathrm{n}^{\circ}$ 216, de 15 de setembro de 2004, considerando o Regulamento Técnico de Boas Práticas para Serviços de Alimentação (BRASIL, 2002; BRASIL, 2004). Os itens averiguados foram: edificações e instalações (78 itens); equipamentos, móveis e utensílios (21 itens); manipuladores (14 itens); e produção e transporte do alimento (33 itens). Entre as opções de resposta estavam "Conforme", "Não conforme" ou "Não se aplica". Os resultados foram tabulados, interpretados e expressos em gráfico de histograma, utilizando o Microsoft@ Office Excel 2013.

\subsection{Amostragem dos molhos e análises microbiológicas}

$\mathrm{Na}$ referida lanchonete foi coletado um molho artesanal, elaborado com ingredientes desconhecidos, o qual foi acondicionado em embalagens estéreis de polietileno e hermeticamente vedadas. No comércio local da cidade de PombalPB foi adquirido um molho produzido industrialmente, com características semelhantes ao molho artesanal em estudo. Nos Laboratórios do Centro de Ciência e Tecnologia Agroalimentar (CCTA), da Universidade Federal de Campina Grande (UFCG), campus Pombal-PB, a qualidade microbiológica foi avaliada quanto à contagem de Coliformes a $35^{\circ} \mathrm{C}$, Coliformes a $45^{\circ} \mathrm{C}$ e pesquisa de Salmonella sp., conforme a metodologia recomendada por Silva et al. (2017), que são os parâmetros exigidos pela legislação vigente até dezembro de 2020, de acordo com a ANVISA, RDC $\mathrm{n}^{\circ}$ 12, de 02 de janeiro de 2001 (BRASIL, 2001).

\subsection{Estabilidade físico-química durante o armazenamento}

Os molhos artesanais foram submetidos as condições de armazenamento em temperatura ambiente da cidade de Pombal-PB $\left(29 \pm 4^{\circ} \mathrm{C}\right)$ e de refrigeração, a $4 \pm 2{ }^{\circ} \mathrm{C}$. Nos Laboratórios do CCTA/UFCG, campus Pombal-PB, a estabilidade físico-química foi avaliada durante 12 dias de armazenamento, no tempo inicial (0 dias) e a cada 6 dias. Os parâmetros físico-químicos avaliados, em triplicata, foram: $\mathrm{pH}$ (potenciômetro digital), calibrado com soluções tampão de $\mathrm{pH} 4,0$ e 7,0; Acidez Total Titulável (ATT), através de titulometria com $\mathrm{NaOH}$ 0,1 N e solução alcoólica de fenolftaleína 1\%; e Sólidos Solúveis Totais (SST), através de refratômetro manual, segundo as metodologias descritas pelo Instituto Adolfo 
Lutz (IAL, 2008). A atividade de água (Aw) também foi avaliada, em analisador portátil a $30^{\circ} \mathrm{C}\left(\right.$ Novasina ${ }^{\circledR}$, modelo Labstart).

\subsection{Análise estatística}

Foi utilizado o Teste Shapiro-Wilk para atestar a normalidade dos dados, refutando a hipótese de não normalidade. Os dados obtidos na estabilidade físico-química durante o armazenamento foram analisados com auxílio do software Assistat versão 7.7 beta (SILVA e AZEVEDO, 2016), através de Análise de Variância (ANOVA). Utilizou-se um Delineamento Inteiramente Casualizado (DIC), sendo aplicado em esquema fatorial $3 \times 2$, sendo 3 períodos de armazenamento e 2 condições de temperaturas, comparando-se as médias pelo teste de Tukey a $5 \%$ de significância $(\mathrm{p}<0,05)$.

\section{RESULTADOS E DISCUSSÃO}

\subsection{Avaliação das Boas Práticas de Manipulação}

Na Figura 1 estão apresentados os resultados obtidos a partir do checklist das BPM, durante a preparação do molho artesanal, em uma lanchonete localizada na cidade de Pombal-PB. Percebe-se nos itens que as respostas não conformes destacaram-se com maiores percentuais em relação as demais.

Figura 1: Dados obtidos na avaliação das Boas Práticas de Manipulação, durante a preparação de molho artesanal, em uma lanchonete localizada na cidade de Pombal-PB

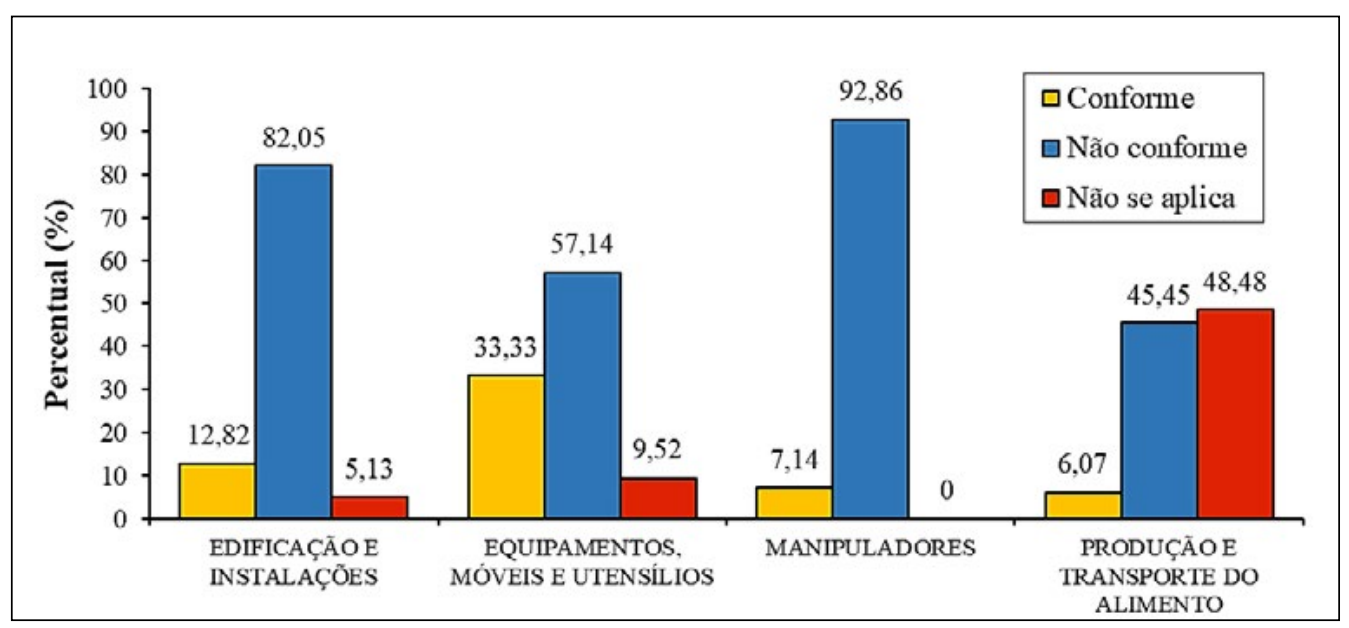

Fonte: Elaborado pelos autores (2019). 
Nas edificações e instalações da lanchonete localizada na cidade de Pombal-PB foram observados $82,05 \%$ de itens não conformes, representados principalmente pela parte externa do estabelecimento. Observou-se inadequações nas portas por não serem automáticas; os banheiros não apresentaram portas e as torneiras não possuíam sistema automático; paredes sem angulação e o ambiente não apresentou ventilação artificial.

Os equipamentos, móveis e utensílios apresentaram 57,14\% de itens não conformes. Estes entram em contato direto com as matérias-primas e insumos, durante a manipulação ou fabricação dos produtos alimentícios, sendo passíveis de contaminação cruzada e interferindo na qualidade final. Resultados semelhantes foram obtidos por Sattler et al. (2017), com 33,33\% de itens adequados, estando insatisfatória a estrutura física de unidades de alimentação, em Lourenço do Oeste-SC.

Para os manipuladores, observou-se $92,86 \%$ de itens não conformes, devido à falta de higienização pessoal, programas de capacitação e supervisão, ausência de uniformes limpos e com cores claras, assim como porque os manipuladores não utilizavam equipamentos de proteção individual. Já Ferraz et al. (2014), avaliando as Boas Práticas de Fabricação em uma indústria paulista de doces tradicionais, observaram apenas $23,10 \%$ de itens não conformes.

Os itens de produção e transporte do alimento demonstraram altos percentuais de "Não se aplica", pois a lanchonete realiza mais vendas in loco do que por entregas domiciliares. Os itens não conformes $(45,45 \%)$ decorreram da falta de inspeção dos alimentos, ausência do controle do produto final, mal armazenamento e falta de controle na circulação e acesso do pessoal.

\subsection{Análises microbiológicas dos molhos}

Na Tabela 1 estão apresentados os resultados obtidos nas análises microbiológicas dos molhos artesanal, produzido em uma lanchonete localizada na cidade de Pombal-PB, e industrial, adquirido no comércio local.

Tabela 1: Resultados obtidos nas análises microbiológica dos molhos artesanal e industrial

\begin{tabular}{c|c|c|c}
\hline \multirow{2}{*}{ Parâmetros } & \multicolumn{2}{|c|}{ Molhos } & \multirow{2}{*}{ Legislação* } \\
\cline { 2 - 3 } & Artesanal & Industrial & \\
\hline Coliformes a $35^{\circ} \mathrm{C}(\mathrm{NMP} / \mathrm{g})$ & $<3,0$ & $<3,0$ & - \\
\hline Coliformes a $45^{\circ} \mathrm{C}(\mathrm{NMP} / \mathrm{g})$ & $<3,0$ & $<3,0$ & $1,0 \times 10^{2}$ \\
\hline Salmonella sp./25 g & Ausente & Ausente & Ausência \\
\hline
\end{tabular}

*Brasil (2001). NMP - Número Mais Provável.

Fonte: Elaborado pelos autores (2019). 
Apesar dos resultados obtidos com a avalição das BPM, durante a preparação do molho artesanal, os resultados das análises microbiológicas indicaram contagem $<3,0 \mathrm{NMP} / \mathrm{g}$ para Coliformes a 35 e $45^{\circ} \mathrm{C}$. Também foi observado a ausência de Salmonella sp. em $25 \mathrm{~g}$ das amostras. Portanto, os resultados estão de acordo com o preconizado pela $\mathrm{RDC}^{\circ} 12$, de 02 de janeiro de 2001 (BRASIL, 2001).

O contraste entre a avaliação das BPM e os resultados das análises microbiológicas do molho artesanal justifica-se pela condição de preparo do molho. Possivelmente foram aplicados tratamentos térmicos eficientes ou fatores intrínsecos podem ter interferido e desfavorecido a multiplicação dos microrganismos, como a composição físico-química.

$\mathrm{O}$ molho industrial apresentou resultados iguais ao $\mathrm{M}_{\mathrm{A}}$ nos parâmetros microbiológicos analisados, tendo vista que eram esperadas baixas contagens, devido as condições ideais de fabricação que devem ser apresentadas pelas indústrias alimentícias. Casemiro e Martins (2016), ao avaliarem maioneses caseiras comercializadas em carrinhos de cachorro-quente em Tubarão-SC, observaram que $100 \%$ das amostras apresentaram contagens de Coliformes a $35^{\circ} \mathrm{C}$ acima do preconizado pela legislação.

Semelhante a este trabalho, Rudakoff et al. (2018) observaram nas análises microbiológicas que os alimentos servidos aos escolares não apresentaram riscos à saúde. Porém, ainda são necessárias ações a fim de minimizar o risco sanitário, em unidades de alimentação e nutrição escolares da rede municipal de educação de São Luís - MA.

\subsection{Estabilidade físico-química durante o armazenamento}

Na Tabela 2 estão apresentados os resultados obtidos durante o armazenamento do molho artesanal em temperatura ambiente e de refrigeração, visando a verificação do comportamento físico-químico.

Tabela 2: Resultados obtidos durante 12 dias armazenamento do molho artesanal em temperatura ambiente e de refrigeração

\begin{tabular}{|c|c|c|c|c|c|c|}
\hline \multirow{2}{*}{ Parâmetros } & \multirow{2}{*}{$\begin{array}{c}\text { Tempo } \\
\text { (dias) }\end{array}$} & \multicolumn{2}{|c|}{ Molho artesanal } & \multicolumn{3}{|c|}{ Valor de $\mathrm{p}^{1}$} \\
\hline & & $\mathrm{T}^{\circ} \mathrm{C}$ Ambiente & $\mathrm{T}^{\circ} \mathrm{C}$ Refrigeração & A & $\mathrm{T}$ & $\mathrm{A} \times \mathrm{T}$ \\
\hline \multirow{3}{*}{$\mathrm{pH}$} & 0 & $3,72 \pm 0,17$ & $3,72 \pm 0,17$ & \multirow{3}{*}{ ns } & \multirow{3}{*}{ ns } & \multirow{3}{*}{ ns } \\
\hline & 6 & $3,65 \pm 0,03$ & $3,65 \pm 0,01$ & & & \\
\hline & 12 & $3,61 \pm 0,13$ & $3,64 \pm 0,07$ & & & \\
\hline \multirow{3}{*}{$A_{w}$} & 0 & $0,978^{b} \pm 0,002$ & $0,978^{b} \pm 0,002$ & \multirow{3}{*}{ * } & \multirow{3}{*}{ ns } & \multirow{3}{*}{ ns } \\
\hline & 6 & $0,981^{\mathrm{a}} \pm 0,003$ & $0,982^{\mathrm{a}} \pm 0,001$ & & & \\
\hline & 12 & $0,977^{\mathrm{b}} \pm 0,002$ & $0,977^{\mathrm{b}} \pm 0,002$ & & & \\
\hline
\end{tabular}




\begin{tabular}{|c|c|c|c|c|c|c|}
\hline \multirow{2}{*}{ Parâmetros } & \multirow{2}{*}{$\begin{array}{c}\text { Tempo } \\
\text { (dias) }\end{array}$} & \multicolumn{2}{|c|}{ Molho artesanal } & \multicolumn{3}{|c|}{ Valor de $\mathrm{p}^{1}$} \\
\hline & & $\mathrm{T}^{\circ} \mathrm{C}$ Ambiente & $\mathrm{T}^{\circ} \mathrm{C}$ Refrigeração & A & $\mathrm{T}$ & $\mathrm{A} \times \mathrm{T}$ \\
\hline \multirow{3}{*}{$\operatorname{ATT}(\%)$} & 0 & $0,41^{\mathrm{cA}} \pm 0,01$ & $0,41^{\mathrm{bA}} \pm 0,01$ & \multirow{3}{*}{$* * *$} & \multirow{3}{*}{ *** } & \multirow{3}{*}{$* * *$} \\
\hline & 6 & $0,45^{\mathrm{bA}} \pm 0,07$ & $0,41^{\mathrm{bB}} \pm 0,02$ & & & \\
\hline & 12 & $0,67^{\mathrm{aA}} \pm 0,26$ & $0,45^{\mathrm{aB}} \pm 0,05$ & & & \\
\hline \multirow{3}{*}{ SST ( ${ }^{\circ}$ Brix $)$} & 0 & $10,03^{\mathrm{bA}} \pm 0,15$ & $10,03^{\mathrm{aA}} \pm 0,15$ & \multirow{3}{*}{$* *$} & \multirow{3}{*}{ * } & \multirow{3}{*}{ ns } \\
\hline & 6 & $10,73^{\mathrm{aA}} \pm 0,23$ & $10,33^{\mathrm{aB}} \pm 0,32$ & & & \\
\hline & 12 & $10,73^{\mathrm{aA}} \pm 0,21$ & $10,32^{\mathrm{aB}} \pm 0,15$ & & & \\
\hline
\end{tabular}

${ }^{1}$ Significância estatística da ANOVA: ${ }^{* * *}(p<0,001),{ }^{* *}(p<0,01),{ }^{*}(p<0,05)$ e ${ }^{\text {ns }}($ não significativo $)$. A - Períodos de armazenamento, $\mathrm{T}$ - Condições de temperatura, $\mathrm{A} \times \mathrm{T}$ - Interação entre fatores. pH - Potencial Hidrogeniônico, $\mathrm{A}_{\mathrm{w}}$ - Atividade de água, ATT - Acidez Total Titulável, SST Sólidos Solúveis Totais. Média \pm desvio-padrão. Letras maiúsculas diferentes na mesma linha ou minúsculas diferentes na mesma coluna diferem significativamente entre si $(p<0,05)$.

Fonte: Elaborado pelos autores (2019).

Foi observado efeito significativo da interação apenas nos valores de ATT $(p<0,001)$. A condição de temperatura do molho artesanal apresentou efeito não significativo $(\mathrm{p}>0,05)$ apenas nos valores de $\mathrm{pH}$ e $\mathrm{A}_{\mathrm{w}}$. Não houve impacto significativo $(\mathrm{p}>0,05)$ dos períodos de armazenamento apenas no parâmetro $\mathrm{pH}$.

$\mathrm{O}$ pH associado a atividade de água dos alimentos são fatores importantes na limitação da multiplicação de alguns tipos de microrganismos e reações de deterioração, durante o armazenamento (SANTOS et al., 2019). Os valores de $\mathrm{pH}$ do molho artesanal indicaram uma faixa de variação entre 3,61 (ambiente) e 3,72 (ambiente e refrigerado), o que contribuiu para os baixos valores microbiológicos (Tabela1). Em molho tipo maionese fresco e preparado comercialmente, o $\mathrm{pH}$ baixo $(\leq 4,0)$ inibiu a cultura de Salmonella após curta incubação (KEERTHIRATHNE et al., 2019). A literatura não estabelece uma faixa ideal de atividade de água para os molhos alimentícios, que denotou diferenças significativas $(p<0,05)$ durante o armazenamento entre o tempo de 6 dias e os demais, que não diferiram entre si.

Em relação aos valores de ATT do molho artesanal, não foram observadas diferenças significativas $(p>0,05)$ apenas entre as condições de temperatura no tempo inicial ( 0 dias). $\mathrm{O}$ molho em temperatura ambiente apresentou maiores valores nos tempos 6 e 12 dias de armazenamento. Ao decorrer do armazenamento, os valores de ATT aumentaram gradativamente no molho artesanal em temperatura ambiente, enquanto em temperatura de refrigeração houve aumento significativo $(\mathrm{p}<0,05)$ apenas após 12 dias de armazenamento, pois manteve-se constante entre 0 e 6 dias. Semelhante a esta pesquisa no tempo inicial, Mendes et al. (2016) determinaram a qualidade de maionese e obtiveram valor de ATT de 0,49\%. De acordo com Cassani et al. 
(2019), os alimentos com caráter ácido são menos suscetíveis a multiplicação bacteriana.

Para os teores de SST do molho artesanal, apenas no tempo inicial (0 dias) não houveram diferenças significativas $(p>0,05)$ entre as condições de temperatura, posto que o molho em temperatura ambiente apresentou maiores valores nos tempos 6 e 12 dias de armazenamento. Ao longo do período de armazenamento, houve aumento significativo $(\mathrm{p}<0,05)$ apenas nos valores de SST do molho em temperatura ambiente, mantendo-se constante entre 6 e 12 dias. Melo et al. (2012), ao avaliarem a vida de prateleira de molho de tomate para pizza, obtiveram teor médio de SST de $8,80^{\circ}$ Brix, independente da temperatura e/ou tempo de armazenamento.

\section{CONCLUSÕES}

A lanchonete localizada na cidade de Pombal-PB classificou-se no grupo 3 de atendimento aos itens, pelo checklist das BPM, durante a preparação de molho artesanal. Evidencia-se a necessidade de uma adequação aos requisitos exigidos para atender a regulamentação dos órgãos competentes, visando a redução do risco sanitário e melhoria da qualidade do produto. Contudo, os itens não conformes referentes as condições higiênico-sanitárias inadequadas não levaram a contaminação microbiológica do molho artesanal, que demostrou boa estabilidade principalmente acondicionado em temperatura de refrigeração em até 12 dias de armazenamento.

\section{REFERÊNCIAS}

BELTRÃO, J. C. C.; PEREIRA, L. G.; GONZALEZ, A. G. M. Análise microbiológica e avaliação das Boas Práticas de Fabricação durante o fluxograma de processamento do repolho branco (Brassica oleracea var. capitata $\mathrm{f}$. alba) cru servido em um restaurante self-service. Vigilância Sanitária em Debate, v. 5, n. 4, p. 24-31, 2017. DOI $10.22239 / 2317-269 x .00892$

BRASIL. Agência Nacional de Vigilância Sanitária. Resolução RDC nº. 216, de 15 de setembro de 2004. Regulamento Técnico de Boas Práticas para Serviços de Alimentação. Diário Oficial da União; Poder Executivo, set. 2004.

BRASIL. Agência Nacional de Vigilância Sanitária. Resolução RDC nº. 275, de 21 de outubro de 2002. Regulamento Técnico de Procedimentos Operacionais Padronizados aplicados aos Estabelecimentos Produtores/Industrializadores de Alimentos. Diário Oficial da União; Poder Executivo, out. 2002.

BRASIL. Agência Nacional de Vigilância Sanitária, Ministério da Saúde. Resolução $\mathrm{RDC}^{\circ}$ 49, de 31 de outubro de 2013. Dispõe sobre a regularização para o exercício de atividade de interesse sanitário do microempreendedor individual, do empreendimento familiar rural e do empreendimento econômico solidário e dá outras 
providências. Diário Oficial [da] República Federativa do Brasil, Poder Executivo, Brasília, DF, 01 nov. 2013. Seção 1, 56p.

BRASIL. Ministério da Saúde. Agência Nacional de Vigilância Sanitária. Resolução $\mathrm{RDC}^{\mathrm{o}} 12$, de 12 de janeiro de 2001. Aprova o regulamente sobre padrões microbiológicos para alimentos e seus Anexos I e II. Diário Oficial [da] República Federativa do Brasil, Brasília, jan. 2001.

CÂNDIDO, A. F. M.; FEITOSA, B. F.; ALCÂNTARA, C. M.; OLIVEIRA NETO, J. O.; ARAÚJO, A. S. Condições higiênico-sanitárias e Boas Práticas de Manipulação em quiosques na cidade de Pombal-PB. Higiene Alimentar, v. 33, n. 288/289, p. 17961800, 2019. Disponível em: <http:/ / www.higienista.com.br/wp-content/uploads / Anais-Higienistas-2019_VERS\%C3\%83O-ATUALIZADA-FINAL.pdf $>$.

CASSANI, L.; GOMEZ-ZAVAGLIA, A.; SIMAL-GANDARA, J. Technological strategies ensuring the safe arrival of beneficial microorganisms to the gut: from food processing and storage to their passage through the gastrointestinal tract. Food Research International, v. 129, 2019. DOI 10.1016/j.foodres.2019.108852

CASEMIRO, L. P.; MARTINS, A. N. O. Prevalência de contaminação microbiológica e parasitológica de maioneses caseiras comercializadas em carrinhos de cachorroquente. Revista Brasileira de Análises Clínicas, v. 48, n. 4, p. 394-399, 2016.

Disponível em: <http://www.rbac.org.br/artigos/prevalencia-de-contaminacaomicrobiologica-e-parasitologica-de-maioneses-caseiras-comercializadas-em-carrinhosde-cachorro-quente/>.

CORTESE, R. S. M.; VEIROS, M. B.; FIELDMAN, C. Food safety and hygiene practices of vendors during the chain of street food production in Florianopolis, Brazil: A cross-sectional study. Food Control, v. 62, p. 178-186, 2016. DOI 10.1016/j. foodcont.2015.10.027

FERRAZ, R. R. N.; CANASSA, M.; BARNABÉ, A. S.; FORNARI, J. V. Avaliação do conhecimento de manipuladores de alimentos sobre as Boas Práticas de Fabricação em um supermercado do interior do estado de São Paulo como indicador para melhoria na gestão de pessoas. Revista dos Mestrados Profissionais, v. 3, n. 1, 2014. Disponível em: <https:/ / periodicos.ufpe.br/revistas/RMP/article/view/458/514>.

FORTES, K. S. B.; BRASIL, C. C. B.; SILVA, J. P.; PONTES, B. D.; GRAUPE, M. L. Condições higiênico-sanitárias de unidades de alimentação e nutrição de escolas de educação infantil de Palmeira das Missões - RS. Vigilância Sanitária em Debate, v. 5, n. 3, p. 37-43, 2017. DOI 10.22239/2317-269x.00959

IAL. Instituto Adolfo Lutz. Métodos físico-químicos para análise de alimentos. $4^{\mathrm{a}}$ ed., $1^{\text {a }}$ ed. Digital, 2008. 1020p. Disponível em: <http:/ / www.ial.sp.gov.br/resources / editorinplace/ial/2016_3_19/analisedealimentosial_2008.pdf?attach=true >.

IBGE. Instituto Brasileiro de Geografia e Estatística. População, 2019. Disponível em: $<$ https://cidades.ibge.gov.br/brasil/pb/pombal/panorama $>$. 
KEERTHIRATHNE, T. P.; ROSS, K.; FALLOWFIELD, H.; WHILEY, H. The Combined effect of $\mathrm{pH}$ and temperature on the survival of Salmonella enterica Serovar Typhimurium and implications for the preparation of raw egg mayonnaise.

Pathogens, v. 8, n. 4, 2019. DOI 10.3390/pathogens 8040218

MACÊDO, M. J. R.; LOPES, J. N. S. Avaliação das Boas Práticas de Fabricação em uma cantina escolar do município de Missão Velha-CE. Revista E-Ciência, v. 6, n. 1, p. 4953, 2018. DOI 10.19095/rec.v6i1.369

MAIA, H. M.; OLIVEIRA, E. N. A.; FEITOSA, B. F.; FEITOSA, R. M.; OLIVEIRA, S. N. Boas Práticas de Fabricação em comércio de produtos de origem animal localizado em Pau dos Ferros - RN. Revista Brasileira de Agrotecnologia, v. 7, n. 2, p. 121-125, 2017. Disponível em: <https://www.gvaa.com.br/revista/index.php/REBAGRO/article/ view $/ 5130 / 0>$.

MEDEIROS, M. G. G. A.; CARVALHO, L. R.; FRANCO, R. M. Percepção sobre a higiene dos manipuladores de alimentos e perfil microbiológico em restaurante universitário. Revista Ciência \& Saúde Coletiva, v. 22, n. 2, p. 383-392, 2017. DOI 10.1590/1413-81232017222.17282015

MELO, S. S.; SILVA, M. C. M.; SANTANA, Y. A. G.; LIMA, A. Formulação, caracterização físico-química, sensorial, microbiológica e vida de prateleira de molho de tomate para pizza. PUBVET, v. 6, n. 15, p. 1352-1356, 2012. DOI 10.22256/pubvet. v6n15.1355

MENDES, M. P.; FORMIGONI, M.; SANTOS, S. S.; MADRONA, G. S. Determinação da qualidade físico-química e instrumental de maionese desenvolvida à base de óleo de coco. Higiene Alimentar, v. 30, n. 260/261, p. 90-93, 2016. Disponível em: <http:/ / docs.bvsalud.org/biblioref/2016/11/2752/260-261-sitecompressed-90-93.pdf $>$.

RUDAKOFF, L. C. S.; MOUCHRECK, A. N.; FROTA, M. T. B. A.; BASTOS, L. S. Qualidade e Segurança Alimentar em unidades de alimentação e nutrição escolares da rede municipal de educação de São Luís, Maranhão. Vigilância Sanitária em Debate, v. 6, n. 3, p. 46-53, 2018. DOI 10.22239/2317-269x.01094

SANTOS, B. A.; TEIXEIRA, F.; AMARAL, L. A.; RANDOLPHO, G. A.; SCHWARZ, K.; SANTOS, E. F.; RESENDE, J. T. V.; NOVELLO, D. Caracterização química e nutricional de polpa de frutas armazenadas sob congelamento. Revista da Universidade Vale do Rio Verde, v. 17, n. 1, p. 1-13, 2019. DOI 10.5892/ruvrd. v17i1.5049.g10951675

SANTOS, E. R. S.; SANTOS, T. C.; SOARES, L. S.; DIAS, R. M. F. Avaliação da aplicação das boas práticas na comercialização de água de coco em quiosques localizados em Salvador, BA. Higiene Alimentar, v. 32, n. 278/279, p. 46-51, 2018. Disponível em: <http:/ / docs.bvsalud.org/biblioref/2018/06/905755/site-278-279-4651.pdf $>$. 
SATTLER, M.; ALEXIUS, S. L.; FRANÇA, V. F. Condições higiênico-sanitárias e estrutura física em unidades de alimentação e nutrição de São Lourenço do Oeste/SC. Nutrição Brasil, v. 16, n. 2, p. 53-60, 2017. DOI 10.33233/nb.v16i2.876

SILVA, F. A. Z.; AZEVEDO, C. A. V. The assistat software version 7.7 and its use in the analysis of experimental data. African Journal of Agricultural Research, v. 11, n. 3, p. 3733-3740, 2016. DOI 10.5897/AJAR2016.11522

SILVA, N.; JUNQUEIRA, V. C. A.; SILVEIRA, N. F. A.; TANIWAKY, N. H.; GOMES, R. A. R.; OKAZARI, M. M. Manual de métodos de análise microbiológica de alimentos e água. 5. ed. São Paulo: Blucher, 2017.

SOUZA, G. C.; SANTOS, C. T. B.; ANDRADE, A. A. Comida de rua: avaliação das condições higiênico-sanitárias de manipuladores de alimentos. Ciência \& Saúde Coletiva, v. 20, n. 8, p. 2329-2338, 2015. DOI 10.1590/1413-81232015208.14922014

VERDUM, D. P.; SILVA, J. P.; COPATTI, F.; BATISTA, M.; PEREIRA, L. S.; KIRSTEN, V. R.; BRASIL, C. C. B. Condições higiênico-sanitárias das cantinas escolares da rede estadual de ensino no município de Palmeira das Missões, Rio Grande do Sul. Vigilância Sanitária em Debate, v. 5, n. 4, p. 17-23, 2017. DOI 10.22239/2317269x.00960 